\title{
Surface Performance Multiobjective Decision of a Cold Roll-Beating Spline with the Entropy Weight Ideal Point Method
}

\author{
F. K. Cui, ${ }^{1,2}$ F. Liu $\left(\mathbb{D},{ }^{1,2}\right.$ Y. X. Su ${ }^{1 D},{ }^{1,2}$ X. L. Ruan, ${ }^{1,2}$ S. K. Xu, ${ }^{1,2}$ and L. B. Liu ${ }^{1,2}$ \\ ${ }^{1}$ School of Mechatronics Engineering, Henan University of Science and Technology, Henan, China \\ ${ }^{2}$ Collaborative Innovation Center of Machinery Equipment Advanced Manufacturing of Henan Province, Luoyang 471003, China \\ Correspondence should be addressed to F. Liu; liufei07104517@163.com
}

Received 21 September 2017; Revised 31 January 2018; Accepted 5 February 2018; Published 4 March 2018

Academic Editor: Nunzio Salerno

Copyright ( $) 2018$ F. K. Cui et al. This is an open access article distributed under the Creative Commons Attribution License, which permits unrestricted use, distribution, and reproduction in any medium, provided the original work is properly cited.

\begin{abstract}
Surface performance is an important indicator of the performance of cold roll-beating spline processing. To obtain the best cold roll spline surface performance (surface roughness, residual stress, and surface hardening degree), multiobjective optimal process parameters must be determined. To this end, this paper takes the cold roll-beating spline as the object of study and carries out a cold roll-beating spline surface performance test study. An ideal algorithm for entropy weight is constructed, and the multiobjective decision of the cold roll-beating spline surface performance is determined by using the entropy weight ideal point algorithm, providing a decision on the cold roll-beating spline processing parameters. The grey correlation algorithm is used for verification, and the results show that the multiobjective decision of the cold roll-beating spline surface performance is feasible by using the constructed entropy weight ideal point algorithm.
\end{abstract}

\section{Introduction}

Cold roll-beating forming technology is an advanced plastic forming technology. Through high-speed rotation of the roller on the spline for continuous rolling and hitting, the metal material is forced to flow along the contour of the roller, gradually forming plastic; this approach is thus a green, nearly net forming, high-performance part processing method [1-3]. The technology has high production efficiency and low cost and requires no cutting or chip production. In the automotive industry, aerospace industry, major strategic equipment industry, and other fields that utilize a spline, gear and screw processing has been widely used $[4,5]$. In the cold roll-beating forming process, the spline surface performance directly affects the use performance of the spline. Therefore, to obtain the best cold roll-beating spline surface performance, multiobjective decision research on the surface performance of a spline is performed to determine the performance of a cold roll-beating spline surface with improved processing indicator parameters, which has important theoretical significance and engineering application value for the processing of cold roll-beating splines.

In terms of metal flow, Cui et al. [6] established the finite element model of spline in the process of cold roll forming according to the principle of cold roll forming and the law of minimum resistance and got the flow rule of each node in the process of cold roll forming. Cui et al. [7] established the contact model of rolling wheel and spline in the process of cold roll forming by the principle of spline cold rolling and obtained the flow path of nodes in the deformation area. In terms of work hardening, Cui et al. [8] explored the mechanism of work hardening on spline surface according to the principle of cold roll forming and made the cold rolling spline test to get the equivalent strain and temperature distribution rule during cold roll forming process. Cui et al. [9] based on the thermal effect generated by rotational speed of different roller wheels, a cold rolling finite element model was built. By analyzing the equivalent stress change caused by thermal effect, the influence rule of thermal effect on work hardening was obtained. In terms of design, $\mathrm{Li}$ et al. [10] improved the cold roll-beating spindle into a split-clamp structure to solve the problem of the frequent impact of spindle in forming process. Ma et al. [11] designed the improved structure of the hobbing wheel based on the interference of the hobbing wheel and the workpiece in the cold rolling forming process of continuous indexing. In terms of deformation force, Yang et al. [12] simulated the cold roll 
forming process with finite element software. By modifying the regression analysis formula, the deformation force of cold rolling was obtained under different technological parameters. Li et al. [13] established the finite element model of the cold rolling of the lead screw by analyzing the forming principle of the cold rolling beating of the screw and got the stress strain and the metal flow rule of the screw rolling cold rolling. In terms of microstructure evolution, Cui et al. [14] carried out the cold roll compression test according to the plastic deformation mechanism, established the relationship between macroscopic deformation and microscopic change, and got the parameters of $40 \mathrm{Cr}$. Cui et al. [15] obtained the Hopkinson compression test under different strain rates and obtained the dynamic response characteristics of the microstructure and the influence of microstructure change on the macroscopic properties of materials at different strain rates. In terms of residual stress, Ding et al. [16] took involute spline as the research object and used the contour method to measure the spatial distribution of residual stress and obtained the change rule between stress and depth.

In summary, many scholars have performed a considerable amount of research on high-speed cold roll-beating experimentally and by studying metal flow, work hardening, design, deformation force, microstructure evolution, and residual stress. However, there are few reports on the decision of cold roll-beating spline processing parameters, and research on the multiobjective decision of cold rollbeating spline surface performance has not been sufficiently reported. Therefore, this paper proposes the use of the entropy weight ideal point method for the surface performance multiobjective decision of a cold roll-beating spline. Based on the results of a cold roll-beating spline test and using the normalized method, the weights of surface roughness, residual stress, and surface hardening are obtained by the entropy weight method. The ideal point method is then used to obtain the experimental order close to the ideal point of proximity and to determine the decision based on the cold roll-beating spline surface performance of the indicators using improved processing parameters, thereby enhancing the surface properties of the cold roll-beating spline.

\section{Cold Roll-Beating Spline Test}

2.1. Test Equipment. The Swiss company GROB's ZRMe9 roll machine was utilized for the cold roll-beating spline test, and the surface roughness was measured using a Leica DCM3D white light copolymer interference microscope. The surface hardness was measured using a HVS-1000A microhardness tester, and the residual stress was measured by the contour method.

2.2. Experiment Material. Spline rough material was used for grade 20 steel, with a normalizing treatment at $910^{\circ} \mathrm{C}$. The main chemical composition of grade 20 steel is shown in Table 1.

2.3. Test Parameters. The cold roll-beating spline has a spool diameter of $35.15 \mathrm{~mm}$, a modulus of $2.5,14$ teeth, a pressure angle of $30^{\circ}$, a tooth high coefficient of 0.5 , and a tooth root high coefficient of 0.7 . The parameters of the cold roll-beating
TABLE 1: Major chemical composition of grade 20 steel (mass fraction, \%).

\begin{tabular}{lcccccc}
\hline $\mathrm{C}$ & $\mathrm{Si}$ & $\mathrm{Mn}$ & $\mathrm{P}$ & $\mathrm{S}$ & $\mathrm{Ni}$ & $\mathrm{Cr}$ \\
\hline 0.20 & $0.17 \sim 0.37$ & $0.35 \sim 0.65$ & $\leq 0.035$ & $\leq 0.035$ & $\leq 0.30$ & $\leq 0.25$ \\
\hline
\end{tabular}

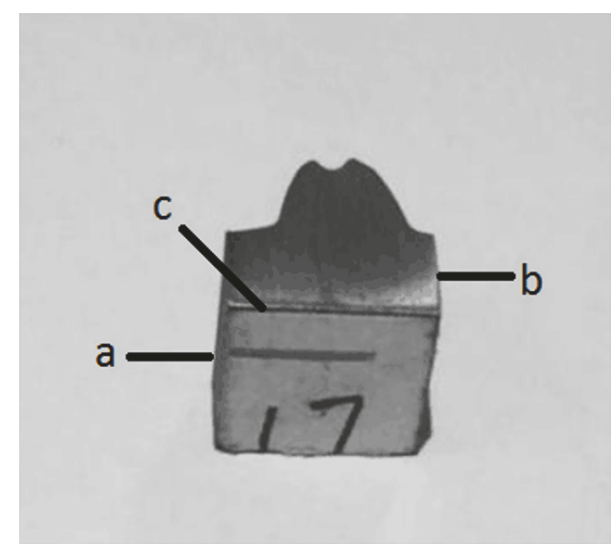

FIGURE 1: Spline sample.

forming process are as follows: the cold roll-beating speed $n$ is $1428,1581,1806,2032$, and $2258 \mathrm{r} / \mathrm{min}$, while the feed rate $f_{1}$ is $21,28,35$, and $42 \mathrm{~mm} / \mathrm{min}$.

\subsection{Experimental Procedure}

2.4.1. Spline Cold Roll-Beating Forming. The ZRMe9 roll machine uses the pull-out method to start the cold rollbeating involute spline and roll-beating wheel symmetrical installation. According to the principle of the cold rollbeating spline [17], when the wheel rotates 14 turns, the workpiece rotates one turn; thus, in order for the roll of the workpiece to hit the same spline slot, the workpiece feed $f$ should be $7 f_{1} / n$.

2.4.2. Surface Roughness Test Process. Using a wire cutting machine, the splines selected as samples were taken, $a=$ $10 \mathrm{~mm}, b=2 \mathrm{~mm}$, and $c=6.79 \mathrm{~mm}$; one sample is shown in Figure 1. The samples were placed under a Leica DCM3D white light copolymer interference microscope, and the measurement area on the sample was selected to be $1.27 \mathrm{~mm} \times 0.42 \mathrm{~mm}$, with the magnification of the microscope set at $250 \mathrm{x}$. To ensure the accuracy of the measurement results, three different parts at each round of the sample were measured separately, and the measured surface profile data were Gaussian-filtered and then separated from the surface roughness data and waviness data. Finally, the average value was obtained and used as the surface roughness value of the sample.

2.4.3. Residual Stress Measurement Process [16, 18-20]. A walking wire was used to cut the machine, cutting a tooth from the cold roll-beating spline (shown in Figure 2) using bronze wire with a diameter of $0.1 \mathrm{~mm}$ at a feed rate of $2 \mathrm{~mm} / \mathrm{min}$ with a feed rate of $0.5 \mathrm{~mm} / \mathrm{min}$ along the shadow 


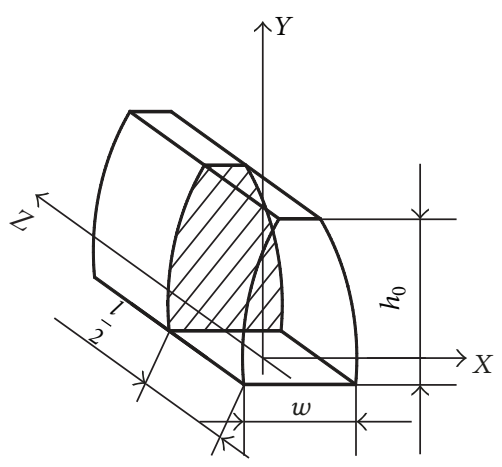

Figure 2: The shape of the specimen and the position of the cross section to be measured.

part of the spline, as shown in Figure 2. A sample was symmetrically cut, with $l=10 \mathrm{~mm}, w=4.35 \mathrm{~mm}$, and $h_{0}=2.68 \mathrm{~mm}$. The contact points on the two sections of the sample shown in Figure 1 were measured using a contact coordinate measuring instrument with a precision of $0.1 \mu \mathrm{m}$ and measurement point spacing of $0.01 \mathrm{~mm} \times$ $0.01 \mathrm{~mm}$. The measured contour data of the two sections were averaged, and the data are fitted with a smooth response surface. The fitted contour surface was applied as a boundary condition to the finite element model established by the spline tooth size obtained by the annealing process. For the finite element calculation, the stress on the cut surface of the obtained annealed sample was equivalent to the residual stress at the same position before the specimen was cut. The use of contour method to measure residual stress steps is very complicated. Even if each step is carried out in strict accordance with operational requirements, there are still some unavoidable factors that interfere with the experimental results. The main error of the contour method in measuring the residual stress is the value of the measured residual stress; the values will generally be slightly smaller during pretreatment release and may be negligible. When cutting the sample, there will be some changes in the stress distribution in the cutting area and we cut cutting speed and discharge current while cutting to avoid the cutting process to maximize the impact of cutting temperature area. In addition, our research group used the crack compliance method and the XRD residual stress measurement method to carry out the related experiments; the results show that the use of contouring method to measure residual stress is found to be more stable. In fact, in order to ensure that the measurement results are more reasonable and rigorous, we use a simulation model based on experimental data for a large number of comparative analyses of this issue. There is a certain degree of deviation between experimental results and simulation results, but the deviation is very small.

2.4.4. Hardening Degree Test Process. The cold roll-beating splines were pulled on the roll machine. The wire cutting machine was used along the direction of the spline to cut into a section of the tooth (as shown in Figure 1). The cut samples were then ground and polished. The HVS-1000 N microhardness tester was used to measure the Vickers hardness at the index circle along the normal surface, and three points at different positions at the same level are measured on this part, with a distance of $0.1 \mathrm{~mm}$ between each measuring point. The load is $1 \mathrm{~N}$ for each measurement and the loading time is $10 \mathrm{~s}$, taking the average of three measurements as the microhardness at this level. Because the degree of hardening is an important indicator when evaluating work hardening, the test results for the surface layer are represented after processing with the microhardness of the surface layer before the microhardness ratio.

2.5. Test Results. The cold roll-beating spline test machining parameters are the roller speed and feed rate. The test results for the tooth surface roughness, the residual stress on the surface of the tooth surface, and the degree of hardening are shown in Table 2.

\section{Multiobjective Decision Algorithm for Entropy Weighted Ideal Point}

From the cold roll-beating spline test results, we can see that the surface roughness, residual stress, and surface hardening of the cold roll-beating spline surface performance for each index differ in each dimension, that multiple indicators affect the surface performance of the cold roll-beating spline, and that each indicator has a different degree of impact on the surface properties of the cold roll-beating spline. The cold rollbeating spline test results are impacted by so many features that it is difficult to find an improved decision for the cold roll-beating spline surface performance indicators of the processing parameters based solely on the test results of the cold roll-beating spline. Therefore, combining a limited number of evaluation objects and an idealized goal of the degree of proximity to evaluate the advantages and disadvantages of each object, a multiobjective decision algorithm for entropy weight ideal points is proposed. The multiobjective decision algorithm for the entropy weight ideal points is shown in Figure 3.

\section{Research on the Surface Performance Multiobjective Decision of a Cold Roll-Beating Spline with the Entropy Weight Ideal Point Method}

4.1. Normalized Method. In Table 2, the dimensions of roughness, residual stress, and surface hardening are different in the three columns of data. To normalize the three datasets,

$$
P_{i j}=\frac{r_{i j}}{\sum_{i=1}^{m} r_{i j}} \quad(i=1,2, \ldots, 20 ; j=5,6,7),
$$

where $P_{i j}$ is the result of normalization for the $i$ th row and $j$ th column and $r_{i j}$ presents test result data for the $i$ th row and $j$ th column.

Applying formula (1) to the results in Table 2 for the surface roughness, residual stress, and surface hardening, we can normalize the results obtained by the cold 
TABLE 2: Cold roll-beating processing test results.

\begin{tabular}{|c|c|c|c|c|c|c|}
\hline $\begin{array}{l}\text { Test } \\
\text { order }\end{array}$ & $\begin{array}{l}\text { Rolling wheel } \\
\text { speed ( } \mathrm{r} / \mathrm{min})\end{array}$ & $\begin{array}{c}\text { Feed rate } f_{1} \\
(\mathrm{~mm} / \mathrm{min})\end{array}$ & $\begin{array}{c}\text { Feed rate } f \\
(\mathrm{~mm} / \mathrm{r})\end{array}$ & $\begin{array}{l}\text { Surface roughness } \\
(\mu \mathrm{m})\end{array}$ & $\begin{array}{c}\text { Residual stress } \\
(\mathrm{MPa})\end{array}$ & $\begin{array}{c}\text { Degree of } \\
\text { hardening (\%) }\end{array}$ \\
\hline 1 & 1428 & 21 & 0.103 & $0.469 \pm 0.0032$ & $-67.42 \pm 6.35$ & $140.96 \pm 2.26$ \\
\hline 2 & 1428 & 28 & 0.137 & $0.479 \pm 0.0028$ & $-72.70 \pm 4.25$ & $143.35 \pm 2.14$ \\
\hline 3 & 1428 & 35 & 0.172 & $0.530 \pm 0.0017$ & $-79.38 \pm 3.36$ & $145.83 \pm 1.97$ \\
\hline 4 & 1428 & 42 & 0.206 & $0.625 \pm 0.0006$ & $-83.01 \pm 2.58$ & $148.71 \pm 1.64$ \\
\hline 5 & 1581 & 21 & 0.093 & $0.440 \pm 0.0034$ & $-68.76 \pm 5.47$ & $140.25 \pm 2.31$ \\
\hline 6 & 1581 & 28 & 0.124 & $0.449 \pm 0.0027$ & $-75.16 \pm 4.42$ & $143.06 \pm 2.05$ \\
\hline 7 & 1581 & 35 & 0.155 & $0.467 \pm 0.0018$ & $-78.79 \pm 3.86$ & $144.91 \pm 1.93$ \\
\hline 8 & 1581 & 42 & 0.186 & $0.508 \pm 0.0012$ & $-83.11 \pm 2.71$ & $146.79 \pm 1.76$ \\
\hline 9 & 1806 & 21 & 0.081 & $0.383 \pm 0.0037$ & $-72.15 \pm 5.13$ & $138.78 \pm 2.35$ \\
\hline 10 & 1806 & 28 & 0.109 & $0.397 \pm 0.0029$ & $-75.65 \pm 4.65$ & $142.26 \pm 2.01$ \\
\hline 11 & 1806 & 35 & 0.136 & $0.442 \pm 0.0016$ & $-79.49 \pm 3.03$ & $143.48 \pm 1.84$ \\
\hline 12 & 1806 & 42 & 0.163 & $0.495 \pm 0.0014$ & $-84.83 \pm 1.75$ & $145.95 \pm 1.72$ \\
\hline 13 & 2032 & 21 & 0.072 & $0.345 \pm 0.0033$ & $-73.04 \pm 5.56$ & $138.41 \pm 2.39$ \\
\hline 14 & 2032 & 28 & 0.096 & $0.361 \pm 0.0024$ & $-79.04 \pm 4.16$ & $141.43 \pm 2.22$ \\
\hline 15 & 2032 & 35 & 0.121 & $0.433 \pm 0.0016$ & $-82.77 \pm 3.23$ & $142.64 \pm 1.89$ \\
\hline 16 & 2032 & 42 & 0.145 & $0.500 \pm 0.0007$ & $-84.76 \pm 2.53$ & $145.03 \pm 1.59$ \\
\hline 17 & 2258 & 21 & 0.065 & $0.357 \pm 0.0033$ & $-74.75 \pm 5.96$ & $138.11 \pm 2.43$ \\
\hline 18 & 2258 & 28 & 0.087 & $0.368 \pm 0.0023$ & $-78.58 \pm 4.64$ & $139.37 \pm 2.18$ \\
\hline 19 & 2258 & 35 & 0.109 & $0.411 \pm 0.0017$ & $-83.25 \pm 2.28$ & $141.93 \pm 1.97$ \\
\hline 20 & 2258 & 42 & 0.130 & $0.472 \pm 0.0009$ & $-84.87 \pm 1.82$ & $144.11 \pm 1.81$ \\
\hline
\end{tabular}

roll-beating spline surface performance indicators of the data normalization matrix $V$ :

$$
V=\left[\begin{array}{lll}
0.05251 & 0.04318 & 0.04937 \\
0.05363 & 0.04656 & 0.05021 \\
0.05934 & 0.05084 & 0.05108 \\
0.06998 & 0.05316 & 0.05209 \\
0.04927 & 0.04403 & 0.04913 \\
0.05027 & 0.04813 & 0.05011 \\
0.05229 & 0.05046 & 0.05076 \\
0.05688 & 0.05322 & 0.05142 \\
0.04288 & 0.04621 & 0.04847 \\
0.04445 & 0.04845 & 0.04983 \\
0.04949 & 0.05091 & 0.05026 \\
0.05543 & 0.05433 & 0.05112 \\
0.03863 & 0.04678 & 0.04848 \\
0.04042 & 0.05062 & 0.04954 \\
0.04848 & 0.05301 & 0.04996 \\
0.05598 & 0.05428 & 0.05081 \\
0.03997 & 0.04787 & 0.04838 \\
0.04121 & 0.05032 & 0.04882 \\
0.04602 & 0.05331 & 0.04971 \\
0.05285 & 0.05435 & 0.05048
\end{array}\right] .
$$

4.2. Entropy Weight Method. Entropy weighting is an objective weighting method based on the entropy weight method, where the entropy weight $w_{j}$ is obtained indirectly from the entropy $e_{j}$. Formula (3) is used to find the entropy $e_{j}$, while formula (4) is used to find the entropy weight $w_{j}$ :

$$
\begin{aligned}
& e_{j}=-k \sum_{i=1}^{m} v_{i j} * \ln v_{i j} \quad\left(k=\frac{1}{\ln m}, m=20\right), \\
& w_{j}=\frac{\left(1-e_{j}\right)}{\sum_{j=1}^{n}\left(1-e_{j}\right)},
\end{aligned}
$$

where $e_{j}$ is the entropy of each index, $k$ is the entropy coefficient, $v_{i j}$ is the normalized data point in the $i$ th row and $j$ th column of $V$, and $w_{j}$ is the entropy weight of each index.

Substituting the data in $V$ in formula (3), the entropy value $e_{j}$ of the surface roughness, residual stress, and surface hardening degree is obtained. Substituting the entropy value $e_{j}$ into formula (4), the entropy weight $w_{j}$ of the surface roughness, residual stress, and surface hardening degree is obtained. The entropy value and entropy weights of the surface properties are shown in Table 3.

\subsection{Ideal Point Method}

4.3.1. Weighted Normalization Matrix. The entropy weights in Table 3 are multiplied by the respective indices corresponding to the data normalization matrix $V$, and 
TABLE 3: Surface performance of the indicators of entropy value and entropy weight.

\begin{tabular}{lccc}
\hline Index & $\begin{array}{c}\text { Surface } \\
\text { roughness }\end{array}$ & $\begin{array}{c}\text { Residual } \\
\text { stress }\end{array}$ & $\begin{array}{c}\text { Degree of } \\
\text { hardening }\end{array}$ \\
\hline Entropy value & 0.9963 & 0.9992 & 0.9999 \\
Entropy weight & 0.8043 & 0.1739 & 0.0217 \\
\hline
\end{tabular}

the weighted normalization matrix $V^{*}$ of the surface performance indicators is obtained:

$$
V^{*}=\left[\begin{array}{lll}
0.04224 & 0.00751 & 0.00107 \\
0.04314 & 0.00810 & 0.00109 \\
0.04773 & 0.00884 & 0.00111 \\
0.05629 & 0.00924 & 0.00113 \\
0.03963 & 0.00766 & 0.00107 \\
0.04044 & 0.00837 & 0.00109 \\
0.04206 & 0.00878 & 0.00110 \\
0.04575 & 0.00926 & 0.00112 \\
0.03449 & 0.00804 & 0.00105 \\
0.03575 & 0.00842 & 0.00108 \\
0.03981 & 0.00885 & 0.00109 \\
0.04458 & 0.00945 & 0.00111 \\
0.03107 & 0.00813 & 0.00105 \\
0.03251 & 0.00880 & 0.00107 \\
0.03899 & 0.00922 & 0.00108 \\
0.04503 & 0.00944 & 0.00110 \\
0.03215 & 0.00832 & 0.00105 \\
0.03314 & 0.00875 & 0.00106 \\
0.03701 & 0.00927 & 0.00108 \\
0.04251 & 0.00945 & 0.00120
\end{array}\right] .
$$

By weighting the normalization matrix $V^{*}$, one can evaluate the surface performance of the indicators of the maximum and minimum values. The ideal solution $Z^{+}$for the surface performance of the indicators corresponds to the largest maximum, while the negative ideal solution $Z^{-}$for the surface performance of the indicators corresponds to the smallest minimum. To this end, we obtain the positive and negative ideal solutions of the surface performance indices:

$$
\begin{aligned}
& Z^{+}=(0.05629,0.00945,0.00113), \\
& Z^{-}=(0.03107,0.00751,0.00105) .
\end{aligned}
$$

4.3.2. Distance between the Surface Performance Indicators and the Positive and Negative Ideal Solutions. Using the weighted normalization matrix $V^{*}$ and the weighted normalization matrix $V^{*}$ corresponding to the positive ideal solution $Z^{+}$and the negative ideal solution $Z^{-}$, formula (7) gives the distance $D_{i}^{+}$between the data in the weighted normalization matrix $V^{*}$ and the positive ideal solution $Z^{+}$.

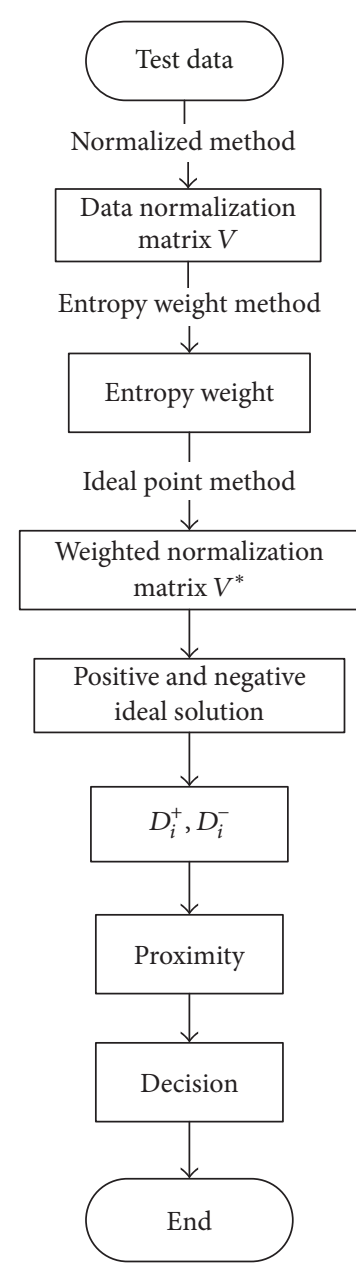

FIGURE 3: Flowchart of the multiobjective decision algorithm for entropy weight ideal points.

Using formula (8), the distance $D_{i}^{-}$between the data in the weighted normalization matrix $V^{*}$ and the negative ideal solution $Z^{-}$is obtained:

$$
\begin{aligned}
& D_{i}^{+}=\sqrt{\sum_{j=1}^{m}\left(V_{i j}^{*}-Z_{j}^{+}\right)^{2}} \quad(i=1,2, \ldots, n ; j=1,2,3), \\
& D_{i}^{-}=\sqrt{\sum_{j=1}^{m}\left(V_{i j}^{*}-Z_{j}^{-}\right)^{2}} \quad(i=1,2, \ldots, n ; j=1,2,3),
\end{aligned}
$$

where $V_{i j}^{*}$ is the element of the $i$ th row and $j$ th column, $Z_{j}^{+}$is the ideal solution of the $j$ th column, and $Z_{j}^{-}$is the negative ideal solution for column $j$.

4.4. Proximity. From formulas (7) and (8), the distance between the data and the ideal solution in the weighted normalized matrix $V^{*}$ is obtained, as is the distance to the 
TABLE 4: Surface performance of the indicators, the distance between the positive and negative ideal solutions, and the test order close to the ideal point of proximity.

\begin{tabular}{lccc}
\hline Test order & $D^{+}$ & $D^{-}$ & $C_{i}$ \\
\hline 1 & 0.01419 & 0.01117 & 0.44 \\
2 & 0.01322 & 0.01208 & 0.48 \\
3 & 0.00858 & 0.01671 & 0.66 \\
4 & 0.00022 & 0.02528 & 0.99 \\
5 & 0.01676 & 0.00856 & 0.34 \\
6 & 0.01589 & 0.009405 & 0.37 \\
7 & 0.01425 & 0.01106 & 0.44 \\
8 & 0.01054 & 0.01478 & 0.58 \\
9 & 0.02184 & 0.00346 & 0.14 \\
10 & 0.02056 & 0.00477 & 0.19 \\
11 & 0.01650 & 0.00884 & 0.35 \\
12 & 0.01171 & 0.01365 & 0.54 \\
13 & 0.02526 & 0.00062 & 0.02 \\
14 & 0.02379 & 0.00194 & 0.08 \\
15 & 0.01730 & 0.00081 & 0.32 \\
16 & 0.01126 & 0.01409 & 0.56 \\
17 & 0.02417 & 0.00135 & 0.05 \\
18 & 0.02316 & 0.00241 & 0.09 \\
19 & 0.01928 & 0.00620 & 0.24 \\
20 & 0.01378 & 0.01160 & 0.46 \\
\hline
\end{tabular}

negative ideal solution. Using formula (9), the proximity of the test order to the ideal point is obtained:

$$
C_{i}=\frac{D_{i}^{-}}{D_{i}^{+}+D_{i}^{-}} \quad(i=1,2, \ldots, n),
$$

where $C_{i}$ is the $i$ th proximity.

4.5. Multiobjective Decision for the Cold Roll-Beating Spline Surface Performance. From formulas (7) and (8), one can obtain the surface performance of the indicators and the distance between the positive and negative ideal solutions. The experimental order obtained by formula (9) is close to the proximity of the ideal point. The results are shown in Table 4.

The relationship between the test order shown in Figure 4 and the corresponding proximity is obtained from Table 4 .

As shown in Figure 4, the corresponding proximity of test order 4 is the best of all the proximities. As shown in Table 2, for test order 4, the corresponding roller speed is $1428 \mathrm{r} / \mathrm{min}$ and the feed rate is $0.206 \mathrm{~mm} / \mathrm{r}(42 \mathrm{~mm} / \mathrm{min})$.

4.6. Verification of the Multiobjective Decision for the Cold Roll-Beating Spline Surface Performance. The grey correlation algorithm was used to calculate the grey correlative degree of the surface roughness, residual stress, and surface hardening degree of the surface performance, based on the order of the test and the grey correlation degree of the size, as shown in Figure 5.

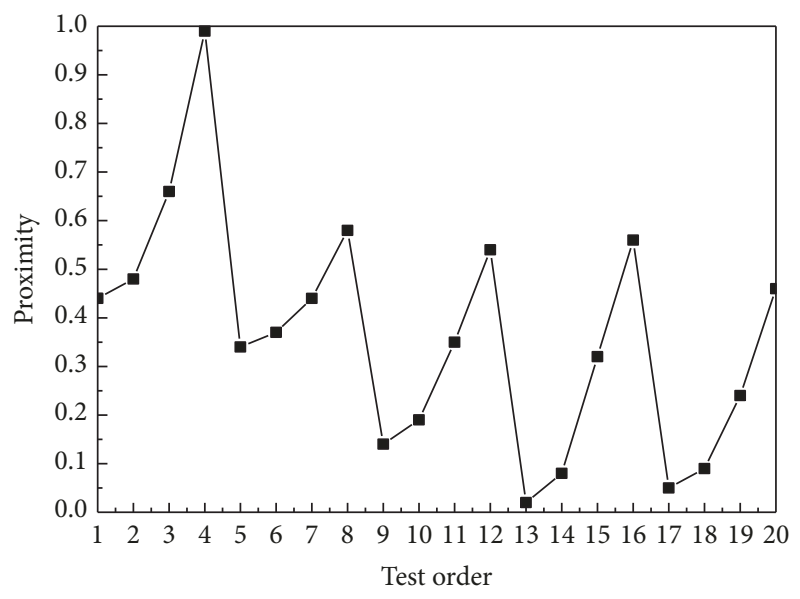

FIGURE 4: Cold roll-beating spline test order and the corresponding proximity.

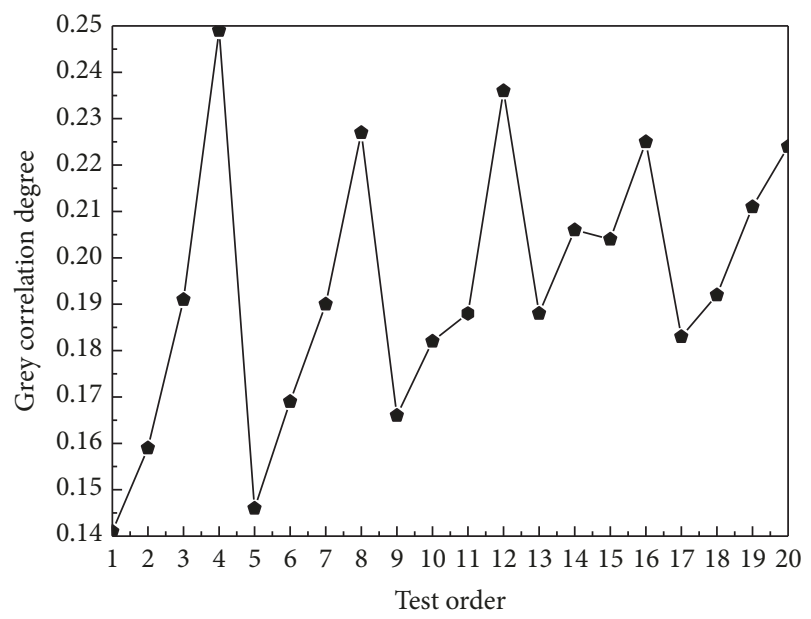

FIGURE 5: Cold roll-beating spline test order and the corresponding grey correlation degree.

Figure 5 shows that test order 4 has a large grey correlation degree, as indicated in Table 2. For test order 4, the corresponding roller speed is $1428 \mathrm{r} / \mathrm{min}$, and the feed rate is $0.206 \mathrm{~mm} / \mathrm{r}(42 \mathrm{~mm} / \mathrm{min})$.

Using the entropy weight ideal point method, an improved proximity is obtained for test order 4 , and the grey correlation algorithm verifies that test order 4 has a large grey correlation degree, allowing better determination of the cold roll-beating spline processing parameters.

\section{Conclusion}

(1) Based on the cold roll-beating spline test results, a multiobjective decision algorithm for entropy weight ideal points is constructed. This algorithm is applied to a physical cold roll-beating spline test, and the proximity of the test order to the ideal solution is obtained.

(2) The proximity of the multiobjective decision algorithm with entropy weight ideal points and the processing parameters of the cold roll-beating spline surface performance are optimized. 


\section{Conflicts of Interest}

The authors declare that they have no conflicts of interest.

\section{Acknowledgments}

The authors are grateful for the financial support received from the National Natural Science Foundation of China (51475146, 51475366, and 51075124).

\section{References}

[1] L. Del Llano-Vizcaya, C. Rubio-Gonzalez, G. Mesmacque, and A. Banderas-Hernández, "Stress relief effect on fatigue and relaxation of compression springs," Materials and Corrosion, vol. 28, no. 4, pp. 1130-1134, 2007.

[2] C. J. Lammi and D. A. Lados, "Effects of residual stresses on fatigue crack growth behavior of structural materials: Analytical corrections," International Journal of Fatigue, vol. 33, no. 7, pp. 858-867, 2011.

[3] T. Furumoto, T. Ueda, M. S. Abdul Aziz, A. Hosokawa, and R. Tanaka, "Study on reduction of residual stress induced during rapid tooling process: Influence of heating conditions on residual stress," Key Engineering Materials, vol. 447, pp. 785-789, 2010.

[4] S. Amirkhanlou, M. R. Rezaei, B. Niroumand, and M. R. Toroghinejad, "High-strength and highly-uniform composites produced by compocasting and cold rolling processes," Materials and Corrosion, vol. 32, no. 4, pp. 2085-2090, 2011.

[5] G. Csiszár, L. Balogh, A. Misra, X. Zhang, and T. Ungár, “The dislocation density and twin-boundary frequency determined by X-ray peak profile analysis in cold rolled magnetron-sputter deposited nanotwinned copper," Journal of Applied Physics, vol. 110, no. 4, Article ID 043502, 2011.

[6] F.-K. Cui, Y.-F. Xie, X.-D. Dong, and L.-M. Hou, "Simulation analysis of metal flow in high-speed cold roll-beating," Applied Mechanics and Materials, vol. 556-562, pp. 113-116, 2014.

[7] F. Cui, X. Wang, F. Zhang, H. Xu, J. Quan, and Y. Li, "Metal flowing of involute spline cold roll-beating forming," Chinese Journal of Mechanical Engineering, vol. 26, no. 5, pp. 1056-1062, 2013.

[8] F. K. Cui, Y. F. Ling, and J. X. Xue, "Research on Workhardening Behavior of Surface Layer of Spline during Cold Rollbeating[J]," Acta Armamentarii, vol. 38, no. 2, pp. 358-366, 2017.

[9] F. K. Cui, K. G. Xie, Y. F. Xie, X. Q. Wang, W. J. Zhu, and Y. Li, "Analysis of coupled thermal-mechanical mechanism based on work hardening phenomenon in high-speed cold roll-beating," Materials Research Innovations, vol. 19, no. S5, pp. 1212-1218, 2015.

[10] L. Li, Y. Li, Y. Yao et al., "Design and Reliability Analysis of Cold Roll-beating Eqipments Spindle Adopted Separate Structure[J]," China Mechanical Engineering, vol. 27, no. 18, pp. 2532-2539, 2016.

[11] Q. Ma, Y. Li, M.-S. Yang, Q.-L. Yuan, and Y.-X. Li, "Structure improvement of roll-beating head for continuous indexing cold roll-beating machine," Binggong Xuebao/Acta Armamentarii, vol. 36, no. 8, pp. 1587-1593, 2015.

[12] M. S. Yang, Y. Li, and Q. L. Yuan, "A Hybird Method to Deformation Force of High-speed Cold Roll-beating Forming [J]," Journal of Digital Information Management, vol. 11, no. 2, pp. 146-153, 2013.
[13] Y. Li, L. Zhang, M. S. Yang, and Q. L. Yuan, "Analysis of lead screw high-speed roll-beating forming," Key Engineering Materials, vol. 455, pp. 151-155, 2011.

[14] F. K. Cui, G. P. Yan, H. Liu, X. Q. Wang, and Y. X. Li, "Study on microstructure evolution during the cold roll-beating of $40 \mathrm{Cr}$," Applied Mechanics and Materials, vol. 490-491, pp. 256-261, 2014.

[15] F. K. Cui, X. D. Dong, X. Q. Wang et al., "The analysis of macroscopic property changes and microstructural evolution of 1020 steel under cold beating," Materials Research Innovations, vol. 19, pp. S156-S161, 2015.

[16] Z. H. Ding, F. K. Cui, Y. B. Liu, Y. Li, and K. G. Xie, "A Model of Surface Residual Stress Distribution of Cold Rolling Spline," Mathematical Problems in Engineering, vol. 2017, Article ID 2425645, 2017.

[17] F. K Cui, Study of High-speed Precise Forming with Cold Rollbeating Technique[D], University of Technology, Xian, 2007.

[18] M. B. Prime, "Cross-sectional mapping of residual stresses by measuring the surface contour after a cut," Journal of Engineering Materials and Technology, vol. 123, no. 2, pp. 162$168,2001$.

[19] P. Pagliaro, M. B. Prime, and J. S. Robinson, "Measuring Inaccessible Residual Stresses Using Multiple Methods and Superposition," Experimental Mechanics, vol. 51, no. 7, pp. 11231134, 2011.

[20] C. Liu and X. Yi, "Residual stress measurement on AA6061-T6 aluminum alloy friction stir butt welds using contour method," Materials and Corrosion, vol. 46, no. 4, pp. 366-371, 2013. 


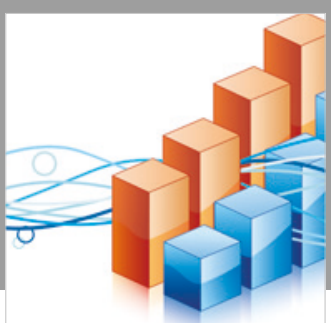

Advances in

Operations Research

\section{-n-m}
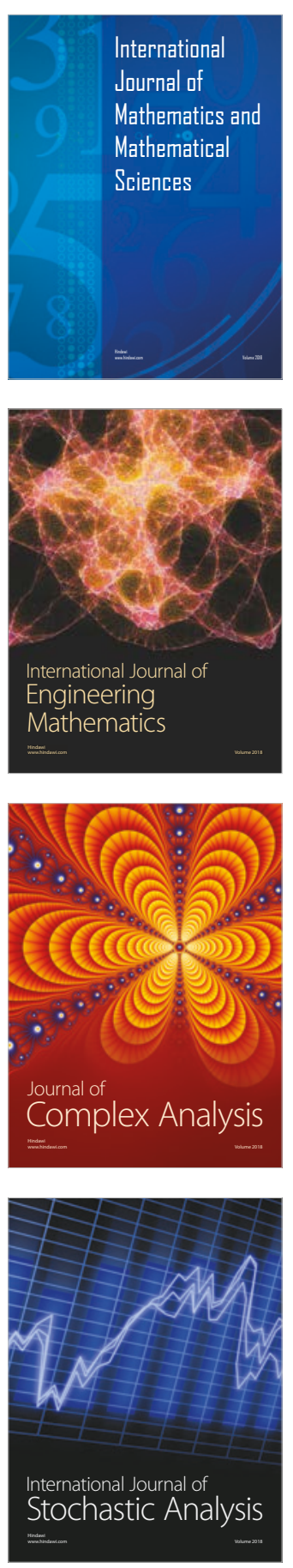
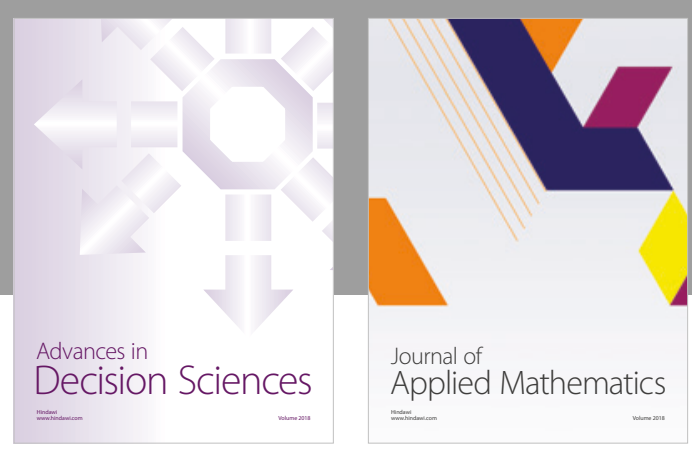

Journal of

Applied Mathematics
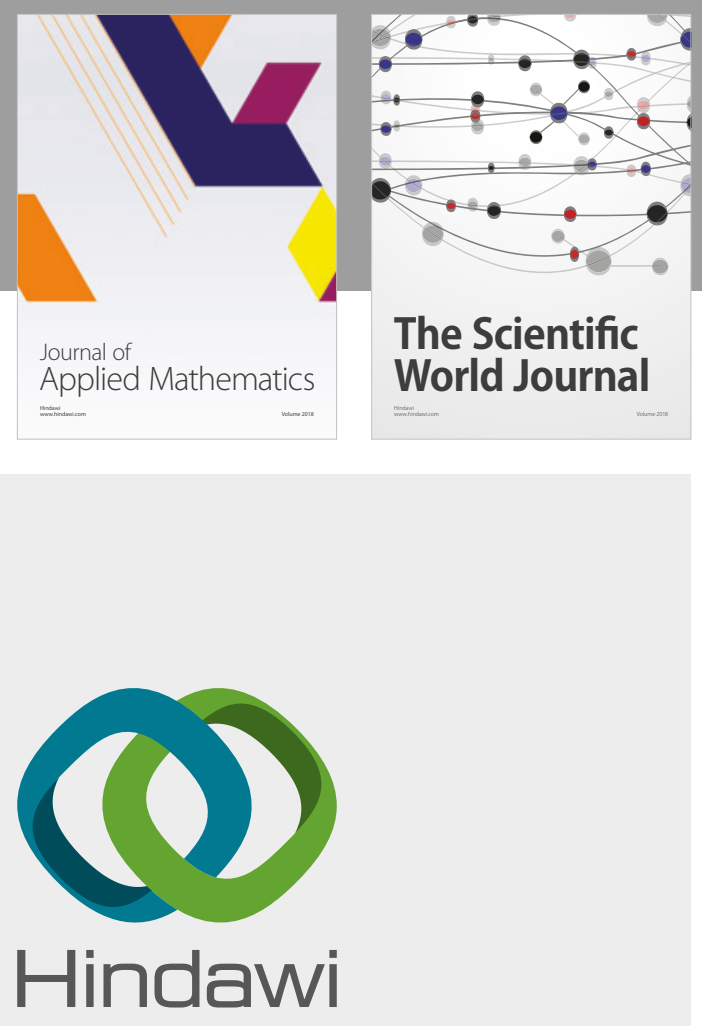

Submit your manuscripts at

www.hindawi.com

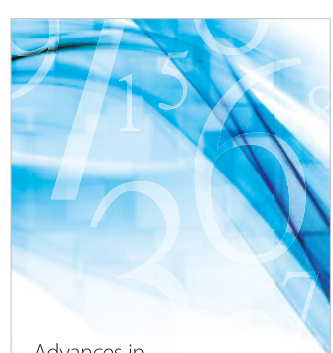

Advances in
Numerical Analysis
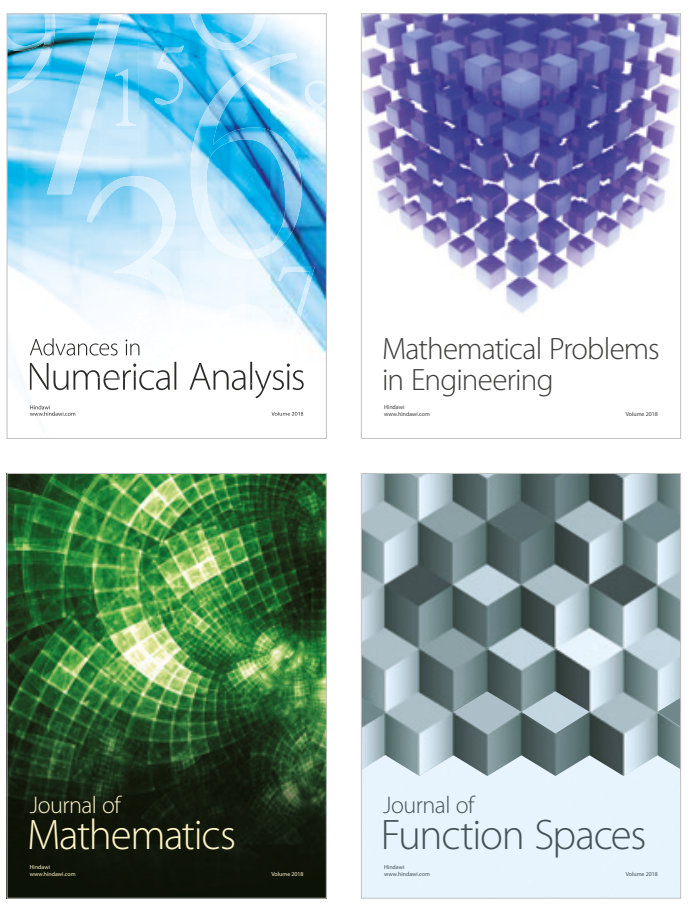

Mathematical Problems in Engineering

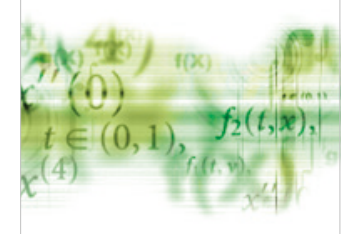

International Journal of

Differential Equations

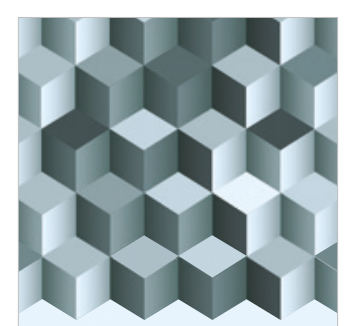

Journal of

Function Spaces

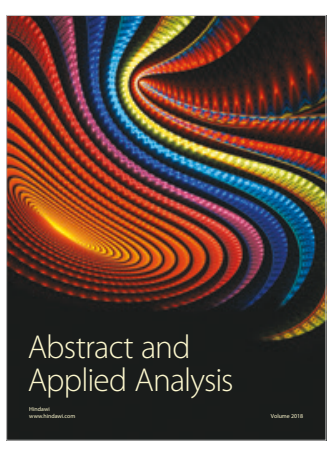

The Scientific

World Journal

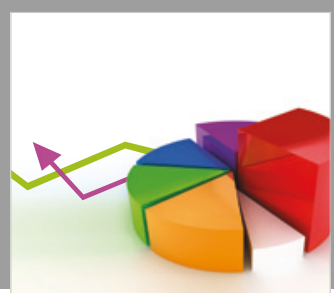

Journal of

Probability and Statistics
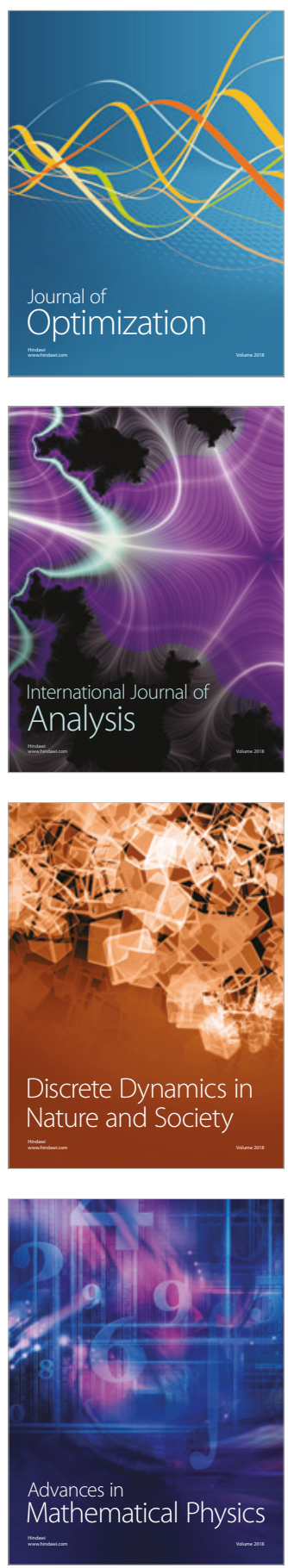